\title{
Skeletal and dental Class II malocclusion, with anterior open bite and accentuated overjet ${ }^{\star}$
}

\author{
Márlio Vinícius de Oliveira'
}

Open bite is defined as a deficiency in normal vertical contact between antagonist teeth and may manifest in a limited region, or more rarely throughout the entire dental arch. If the lack of contact between teeth is located in the incisor and/or canine region when occlusion is in centric relation, it is called anterior open bite (AOB). Some studies have demonstrated that $\mathrm{AOB}$ is strongly associated with non-nutritional sucking habit. This article relates the treatment of a female African-Brazilian patient, with 20 years and 7 months of age, who presented Angle's Class II, division 1 malocclusion, $\mathrm{AOB}$, accentuated overjet, lingual interposition during swallowing and difficulty with pronouncing some phonemes. Orthodontic treatment began by mounting an Edgewise Standard fixed appliance system, with a fixed palatal crib appliance and extraction of maxillary first premolars. This case was presented to the Brazilian Board of Orthodontics and Facial Orthopedics (BBO), as part of the requisites to become a BBO Diplomate.

Keywords: Angle’s Class II malocclusion. Open bite. Tooth extraction.

*Clinical Case Report, Category 7, approved by the Brazilian Board of Orthodontics and Facial Orthopedics (BBO).

${ }^{1}$ Specialist in Orthodontics, Federal University of Alfenas (Unifal). Diplomate from the Brazilian Board of Orthodontics and Facial Orthopedics (BBO).
How to cite this article: Oliveira MV. Skeletal and dental Class II malocclusion, with anterior open bite and accentuated overjet. Dental Press J Orthod. 2012 MarApr;17(2):162-9.

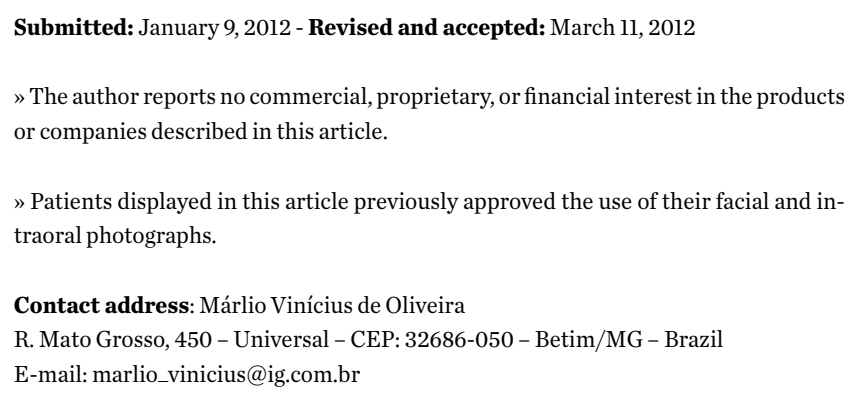




\section{INTRODUCTION}

The patient, a 20 years and 7 months Afro-Brazilian girl, presented for the initial exam in a good state of general health. Her medical and dental history contained no significant records. Her oral hygiene was good and her third molar had been extracted. During anamnesis the patient reported that she had used a pacifier until she was eight years old. Her chief complaint was the "difficulty with pronouncing some words".

\section{DIAGNOSIS}

The patient presented a symmetrical face, convex profile (upper lip $-\mathrm{S}$ line $=7 \mathrm{~mm}$, Lower lip $-\mathrm{S}$ line $=7 \mathrm{~mm}$ ), acute nasolabial angle, lip sealing with contraction of the perioral muscles and chin muscle, lingual interposition when swallowing and difficulty with pronouncing some phonemes. Her smile, in spite of AOB, was pleasant, with a good contour, as well as an adequate exposure of the maxillary incisors.

Regarding her dental aspect, she presented Angle's Class II division 1 malocclusion, $5.5 \mathrm{~mm}$ overjet, a $3 \mathrm{~mm}$ anterior open bite, coincident upper and lower midlines, triangular-shaped maxillary arch and parabolic mandibular arch, both presenting symmetry in the anteroposterior and transverse directions. The patient presented no arch perimeter and Bolton discrepancy (Figs 1 and 2).
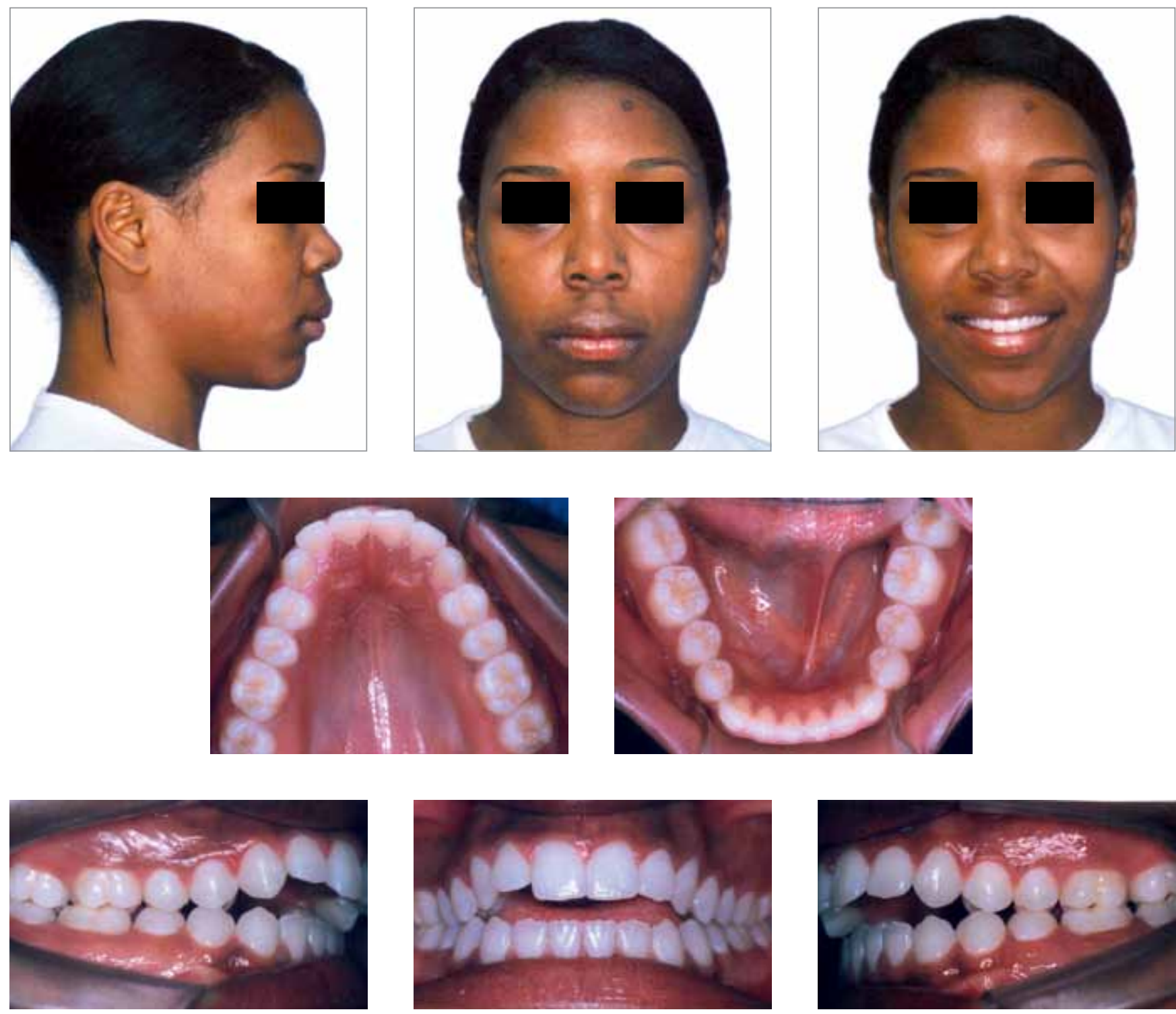

Figure 1 - Initial facial and intraoral photographs. 

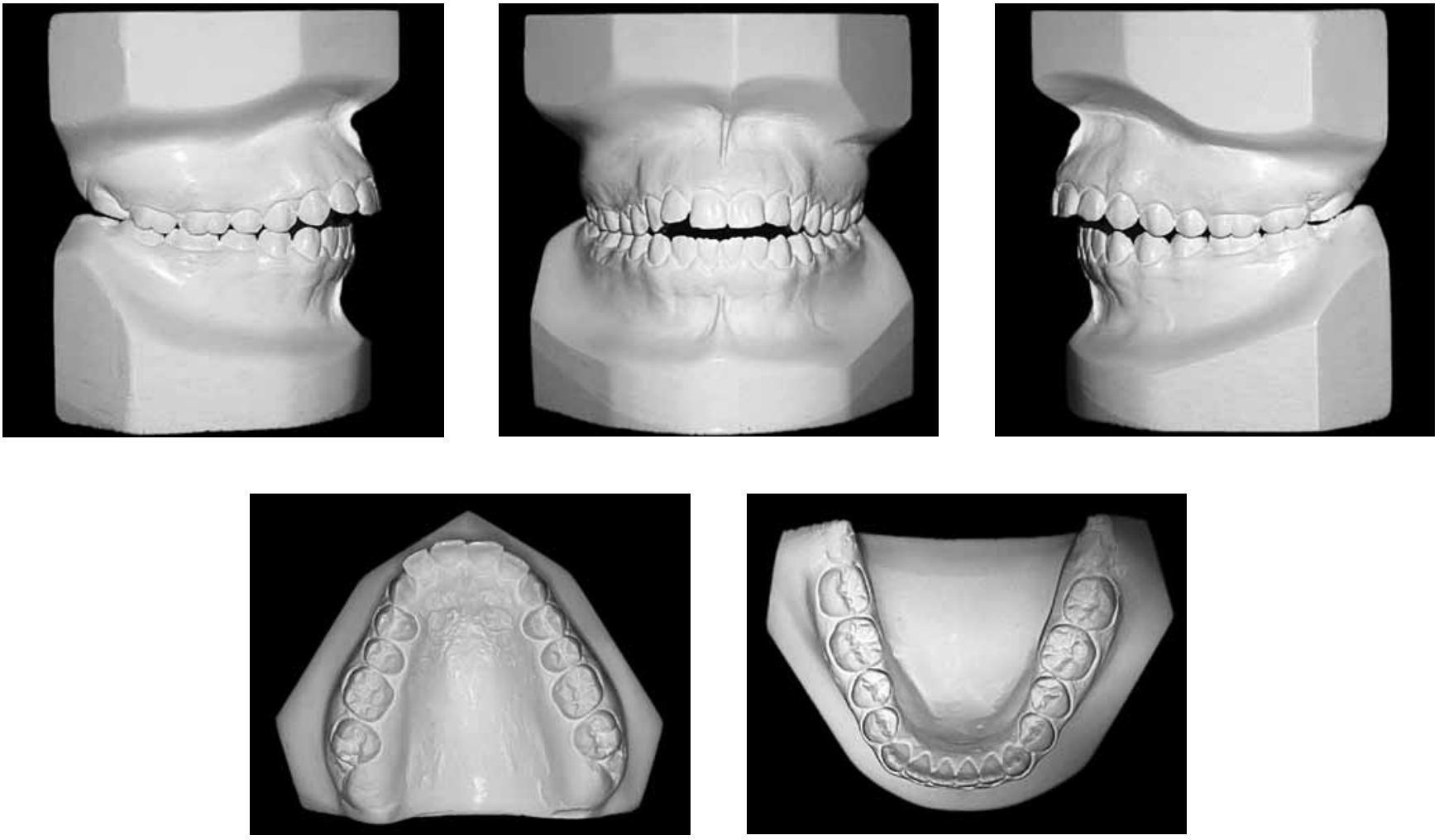

Figure 2 - Initial models.

The periapical and panoramic radiographs disclosed a normal bone, absence of third molars and a good root parallelism. With regard to the skeletal pattern, she presented a $5^{\circ} \mathrm{ANB}$ angle (SNA $=79^{\circ}$ and $\mathrm{SNB}=74^{\circ}$ ), showing evidence of disharmony between the bony bases, according to Steiner's analysis. From the vertical aspect, there was an accentuated inclination of the mandibular plane $\left(\mathrm{SN}-\mathrm{G} . \mathrm{Gn}=40^{\circ}\right)($ Fig 4$)$.

\section{TREATMENT GOALS}

The treatment goals were to establish canine Class I occlusion, correct the AOB, overjet and attain ideal functional occlusion. For this purpose extraction of the maxillary first premolars was necessary. In addition, after closure of the $\mathrm{OAB}$, and speech therapy, facial esthetics were expected to improve as well as the pronunciation of some sounds articulated by the teeth, lips and tongue.

\section{TREATMENT PLAN}

The plan was to correct canine Class II relationship and extract the maxillary first premolars. Regarding anterior open bite, the option was to use the fixed palatal crib during the alignment, leveling and canine retraction phase. When incisor retraction began, the crib was removed and a lower spur was bonded on the lingual face of the incisors. At this time, when $\mathrm{AOB}$ and overjet had diminished, the patient was referred for speech therapy treatment.

The fixed appliance used was of the Edgewise Standard type, slot $0.022 \times 0.028$-in, stainless steel arches from 0.014 to 0.020 -in were used for alignment and leveling, and maxillary canine retraction began in 0.018-in arch. For incisor retraction a $0.019 \times 0.025$-in rectangular stainless steel arch with "bull" loops was used distal to the lateral incisors.

For finishing, a rectangular $0.019 \times 0.025$-in maxillary and mandibular arches were used, with first and third order bends, individualized according to the needs of the case. After the active treatment stage, upper and lower retention appliances would be placed.

\section{TREATMENT PROGRESS}

Orthodontic bands with brackets welded on the buccal region and lingual tubes were adapted to the first maxillary molars. Transfer impressions were taken in order to fabricate the crib appliance. 

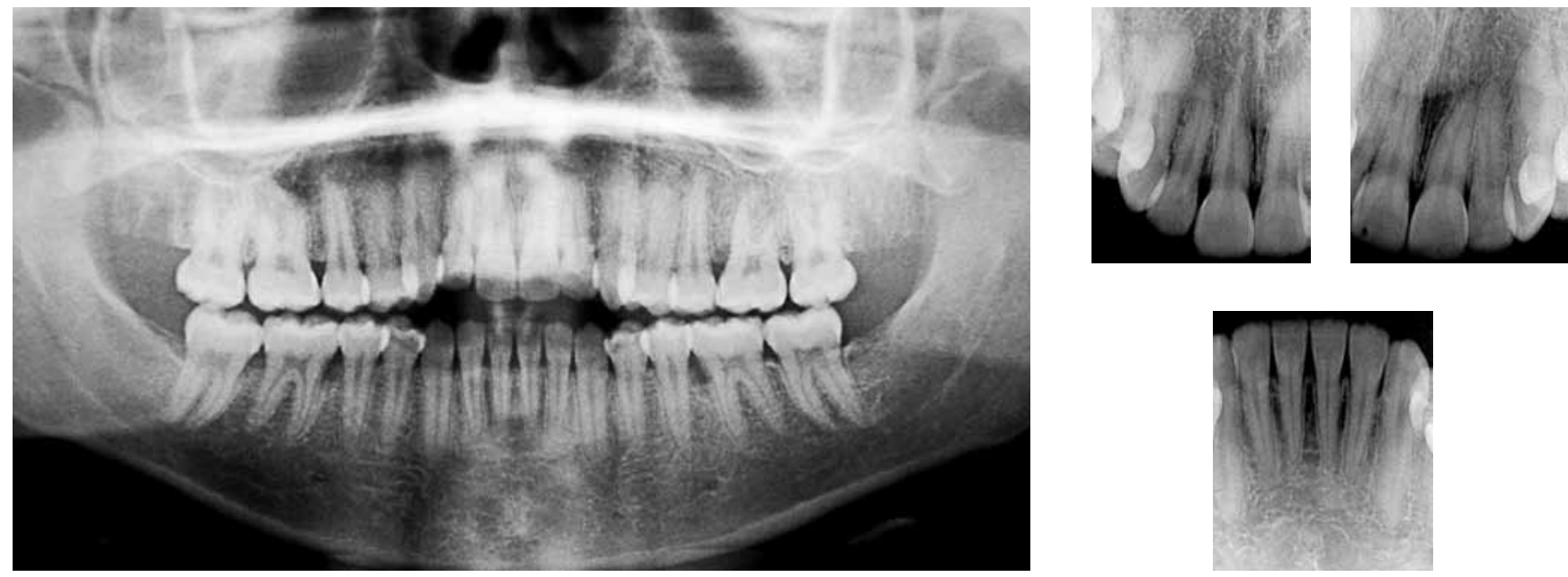

Figure 3 - Initial panoramic and periapical radiographs.
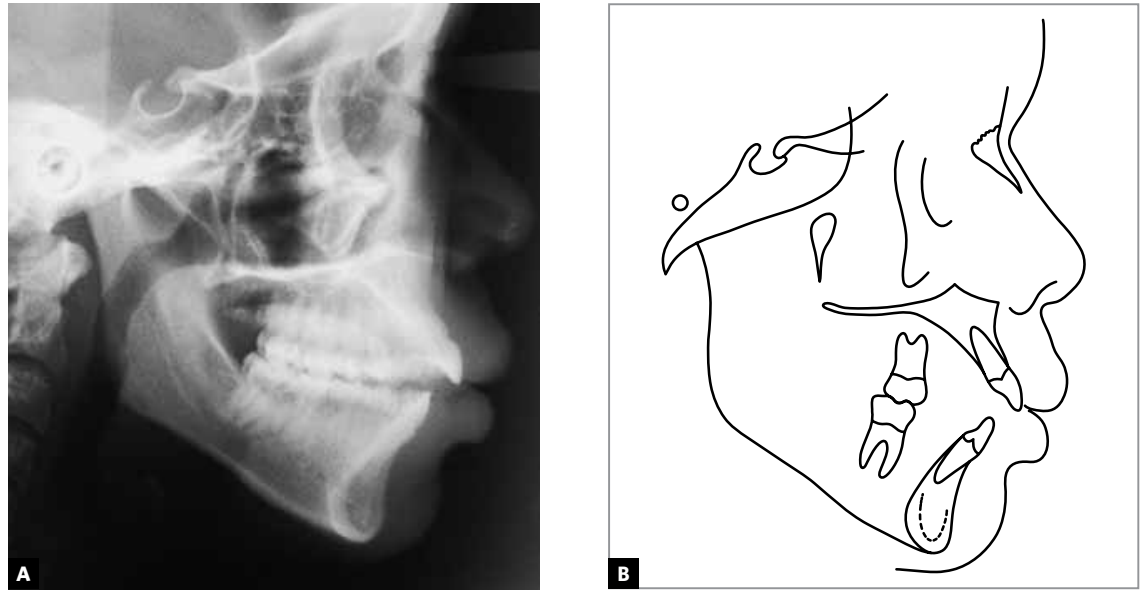

Figure 4 - Initial cephalometric profile radiographs and cephalometric tracings.

After cementation of the orthodontic bands, the crib was fitted into the lingual tubes and tied with metal ligatures (Fig 5). The remainder of the fixed appliance was installed on the maxillary and mandibular dental arches, Edgewise standard system with slot 0.022 x 0.028-in.

After the appliances were installed, extraction of the maxillary first premolars was requested, and in sequence, round stainless steel arches (0.014 and 0.020in) for alignment and leveling were inserted.

In the maxillary arch, the posterior teeth were tied together, on both sides, using 0.018-in wire. Elastic chains were placed from the second premolars to the canines to distalize them. After canine distalization, the stainless steel $0.019 \times 0.025$-in arch made of a rectangular section with bull loops located in the distal region of the lateral incisors for retraction of the canines. At this stage the fixed palatal crib was removed and spurs were bonded on the lingual surface of the mandibular incisors to control tongue position (Fig 6). The patient was referred to speech therapy.

During orthodontic finishing, rectangular $0.019 \times 0.025$-in maxillary and mandibular arches were fabricated, with first and third order bends, individualized according to the needs of the case. At this stage, Class III intermaxillary elastics were used on the left side supported on a maxillary sliding jig for anchorage loss of teeth \#25, \#26 and \#27. Anterior vertical intermaxillary elastics were used, bilaterally, to favor adequate overbite (Fig 8). After the active treatment phase, a maxillary removable wraparound retainer was used, and in the mandibular arch, a fixed retainer bonded from canine to canine was made with a 0.028 -in wire. 


\section{ACHIEVED RESULTS}

When evaluating the patient's records after the end of active treatment, it was observed that the main goals had been attained. Facial esthetics was enhanced by the reduction in lip protrusion, functional balance between the lips resulting from closure of the AOB and speech therapy. The smile remained pleasant in spite of the small increase in exposure of the maxillary incisors (Fig 7).

The maxillary arch shape improved, SNA angle

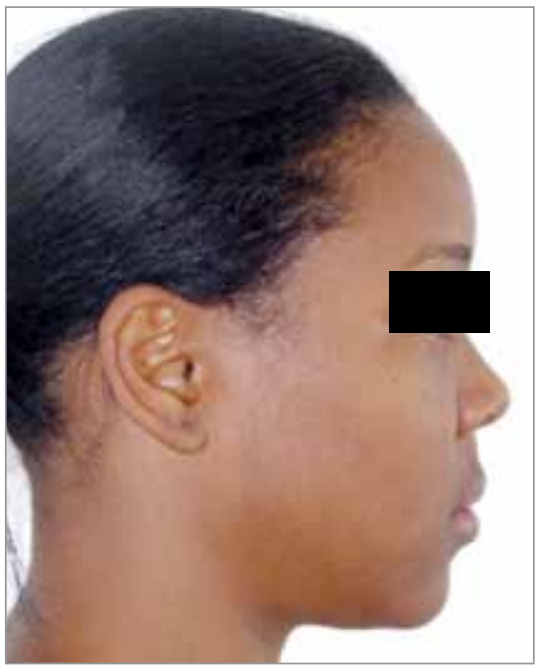

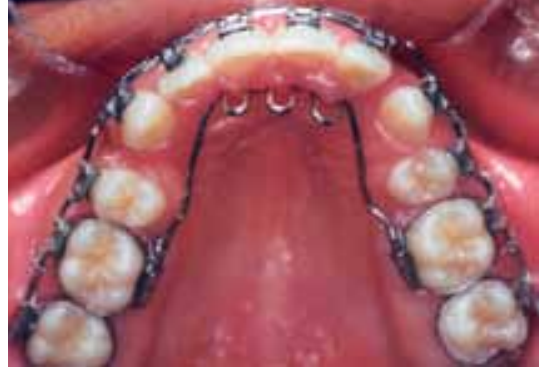

Figure 5 - Fixed palatal crib.

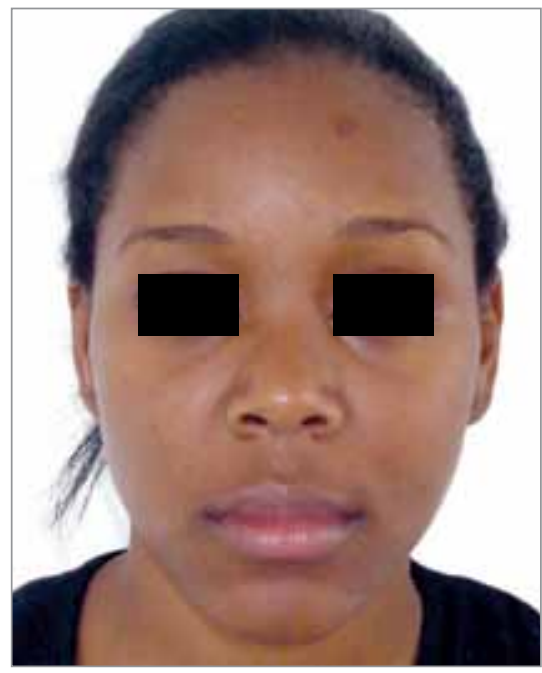

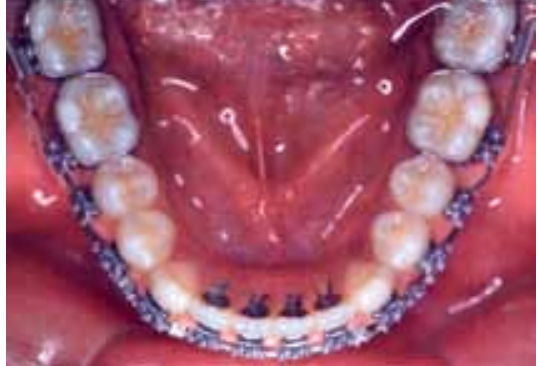

Figure 6 - Bonded mandibular spurs.

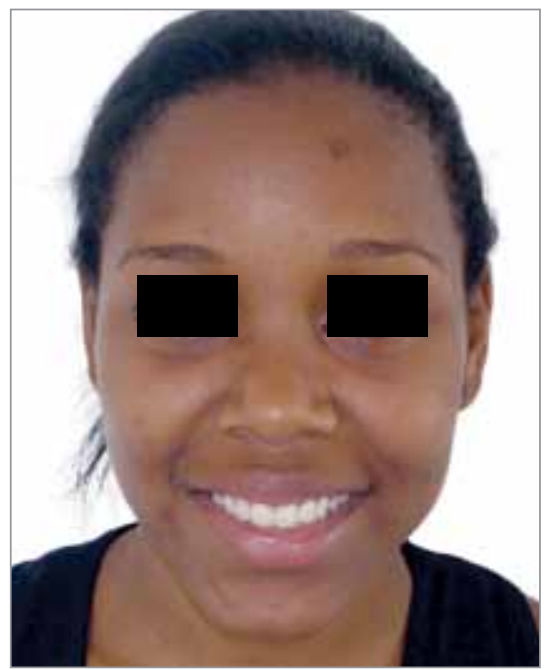

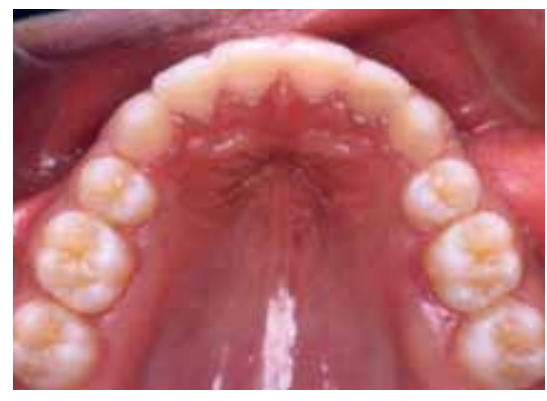
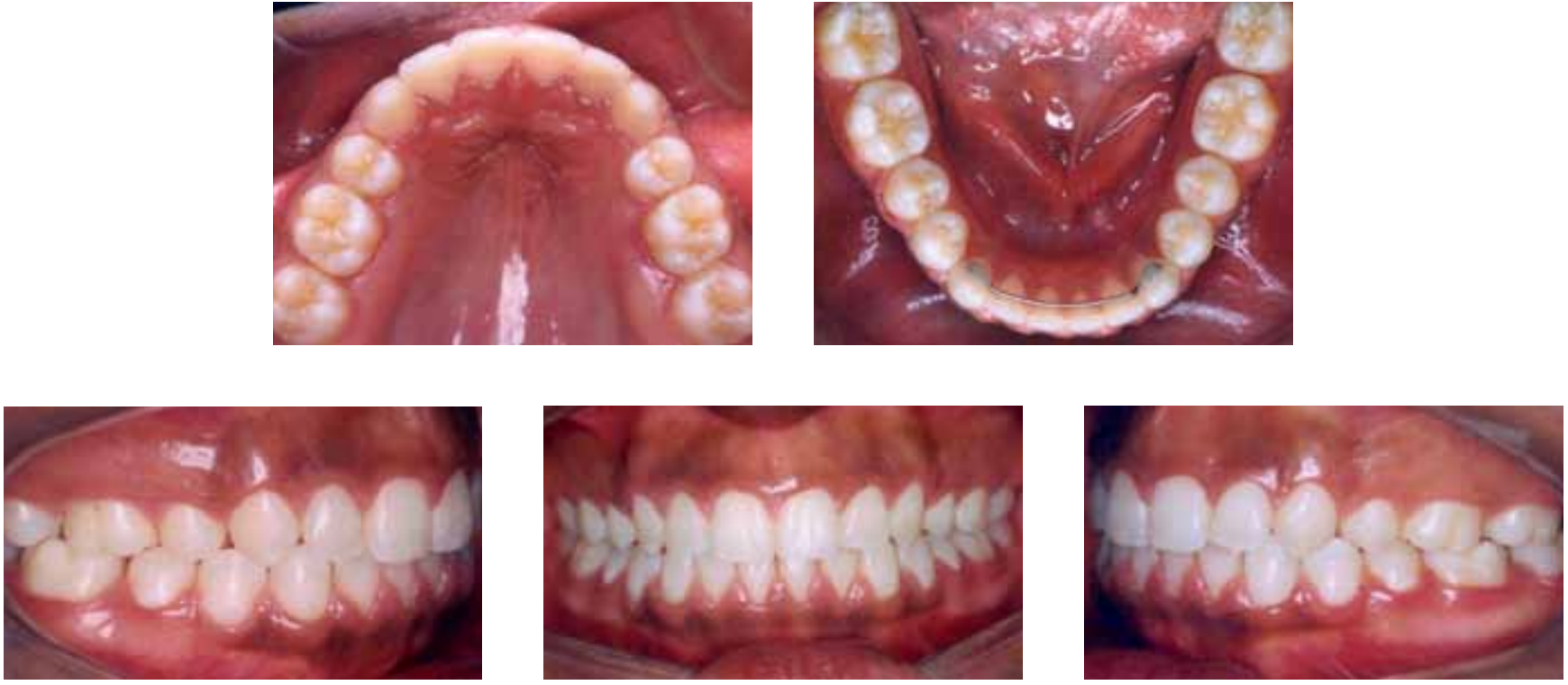

Figure 7 - Final facial and intraoral photographs. 
remained unaltered even with retraction of the incisors. The mandibular position remained vertically unaltered, however, SNB angle increased by 2 degrees, demonstrating a more anterior position at the end of treatment (Fig 10 and Table 1). This anticlockwise rotation of the mandible, verified in the total superimposition of the initial and final tracings (Fig 11), may have occurred as a result of the improvement in the cusp-fossa relationship at the end of treatment, and/or as a result of the loss of anchorage of the maxillary molars.

In the radiographic evaluation discrete apical rounding of the incisors could be perceived, compatible with orthodontic movement (Fig 9). With regard to final occlusion, a Class II molar relationship and Class I canine occlusion were obtained. All the other characteristics of an ideal functional occlusion were verified before the appliance was removed (Fig 8).
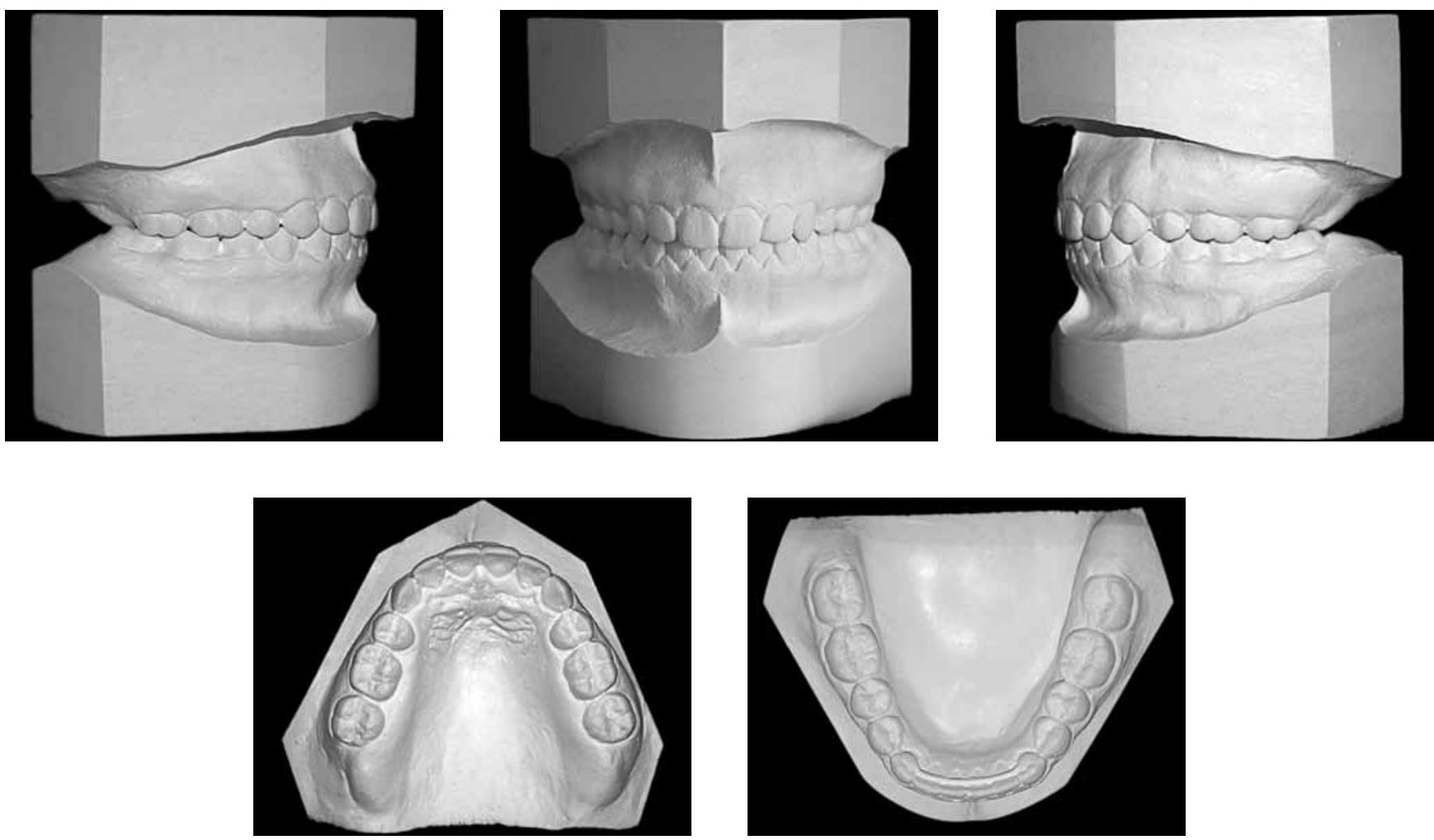

Figure 8 - Final models.
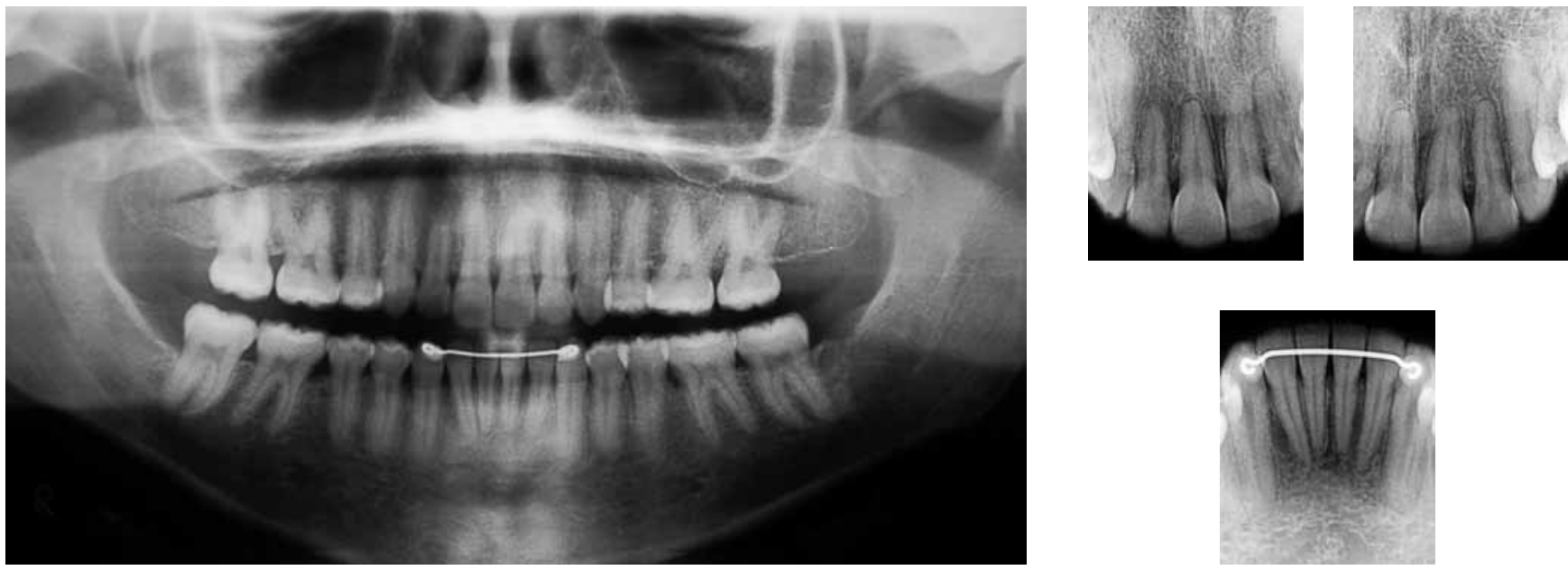

Figure 9 - Final panoramic and periapical radiographs.

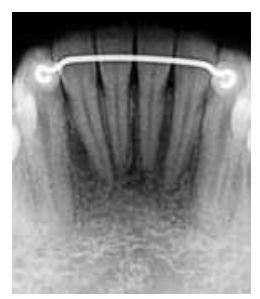



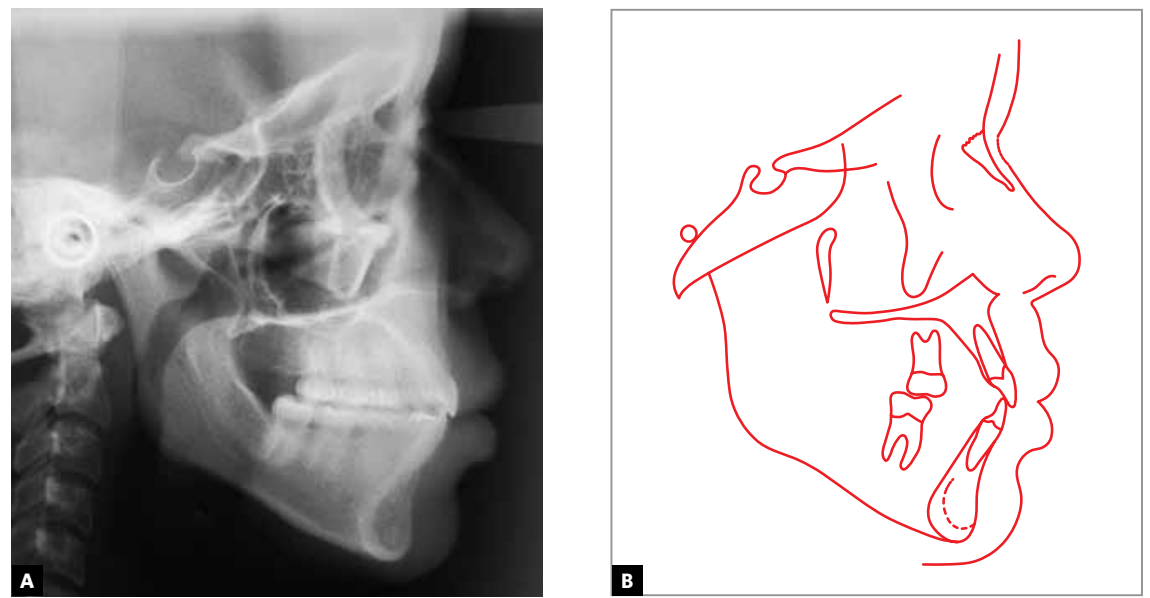

Figure 10 - Final cephalometric profile radiographs and cephalometric tracings.
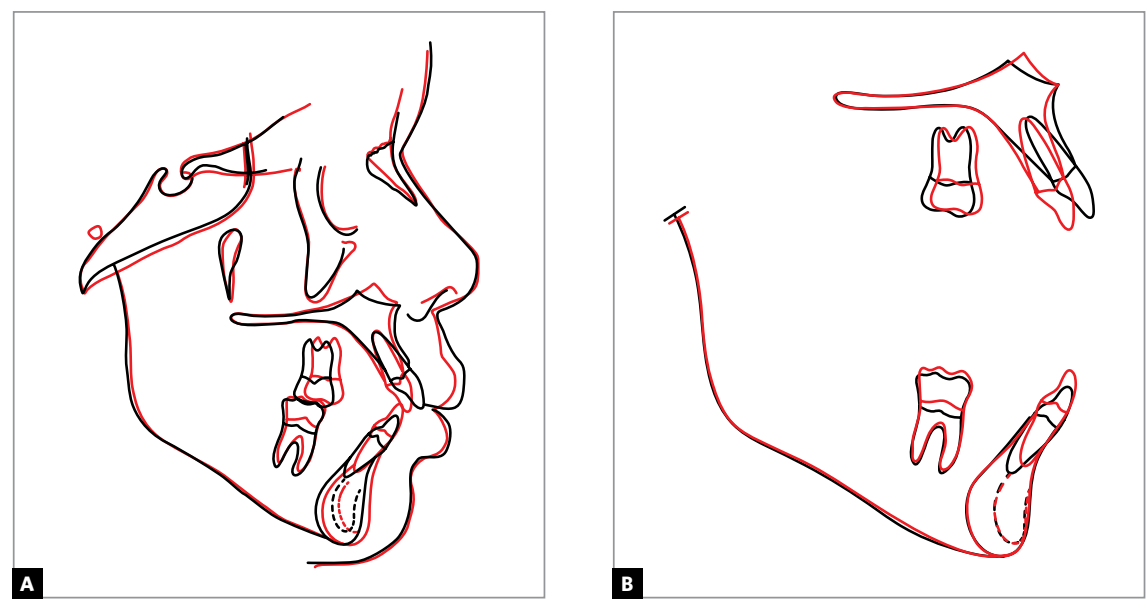

Figure 11 - Total (A) and partial (B) superimpositions of initial (black) and final (red) treatment phases.

Table 1- Summary of cephalometric measurements.

\begin{tabular}{|c|c|c|c|c|c|}
\hline & Measures & Normal & $\mathbf{A}$ & B & A/B Difference \\
\hline \multirow{8}{*}{ Skeletal pattern } & SNA (Steiner) & $82^{\circ}$ & $79^{\circ}$ & $79^{\circ}$ & 0 \\
\hline & SNB (Steiner) & $80^{\circ}$ & $74^{\circ}$ & $76^{\circ}$ & 2 \\
\hline & ANB (Steiner) & $2^{\circ}$ & $5^{\circ}$ & $3^{\circ}$ & 2 \\
\hline & Convexity angle (Downs) & $0^{\circ}$ & $10^{\circ}$ & $6^{\circ}$ & 4 \\
\hline & Y axis angle (Downs) & $59^{\circ}$ & $61^{\circ}$ & $66^{\circ}$ & 5 \\
\hline & Facial angle (Downs) & $87^{\circ}$ & $87^{\circ}$ & $83^{\circ}$ & 4 \\
\hline & SN-GoGn (Steiner) & $32^{\circ}$ & $40^{\circ}$ & $40^{\circ}$ & 0 \\
\hline & FMA (Tweed) & $25^{\circ}$ & 29 & $35^{\circ}$ & 6 \\
\hline \multirow{7}{*}{ Dental pattern } & IMPA (Tweed) & $90^{\circ}$ & $94^{\circ}$ & $88^{\circ}$ & 6 \\
\hline & 1-NA (degrees) (Steiner) & $22^{\circ}$ & $31^{\circ}$ & $22^{\circ}$ & 9 \\
\hline & 1-NA (mm) (Steiner) & $4 \mathrm{~mm}$ & $9 \mathrm{~mm}$ & $6 \mathrm{~mm}$ & 3 \\
\hline & $\overline{1}-N B$ (degrees) (Steiner) & $25^{\circ}$ & $31^{\circ}$ & $25^{\circ}$ & 6 \\
\hline & $\overline{1}-\mathrm{NB}(\mathrm{mm})$ (Steiner) & $4 \mathrm{~mm}$ & $8 \mathrm{~mm}$ & $7 \mathrm{~mm}$ & 1 \\
\hline & $\frac{1}{1}$ - Interincisal angle (Downs) & $130^{\circ}$ & $109^{\circ}$ & $130^{\circ}$ & 21 \\
\hline & $\overline{1}-A P_{0}(\mathrm{~mm})$ (Ricketts) & $1 \mathrm{~mm}$ & $5 \mathrm{~mm}$ & $5 \mathrm{~mm}$ & 0 \\
\hline \multirow{2}{*}{ Profile } & Upper lip - S line (Steiner) & $0 \mathrm{~mm}$ & $7 \mathrm{~mm}$ & $5 \mathrm{~mm}$ & 2 \\
\hline & Lower lip - S line (Steiner) & $0 \mathrm{~mm}$ & $7 \mathrm{~mm}$ & $6 \mathrm{~mm}$ & 1 \\
\hline
\end{tabular}




\section{FINAL CONSIDERATIONS}

Open bite is defined as a deficiency in normal vertical contact between the antagonist teeth, and may be manifested in a limited region, or more rarely, throughout the entire dental arch., ${ }^{1,2}$ If lack of contact of the teeth is located in the region of the incisors and/ or canines, when occlusion is in centric relation, then this is denominated anterior open bite. ${ }^{1,3}$

Some studies have shown that anterior open bite is strongly associated with non-nutritional sucking habit., ${ }^{4,5}$ In the case of this patient, who reported having used a pacifier up to the age of 8 years, it is believed that the open bite was maintained by lingual interposition after pacifier removal. Regarding the functional alteration caused by the anterior open bite, it was planned to use the fixed palatal crib at the beginning of treatment, and afterwards, when the open bite had been reduced, mandibular spurs would be bonded to the lingual surface of the incisors and the patient would be referred for speech therapy.
In this patient, the option was to extract the maxillary first premolars to correct the overjet and Class II canine relationship. Treatment of Class II without extractions requires extensive distal movement of the maxillary posterior teeth, which frequently becomes complicated, particularly in adult patients ${ }^{7}$. Recent studies have demonstrated that for the same age and degree of severity, the protocol for Class II malocclusion treatment with extraction of the two maxillary premolars is more efficient than the treatment protocol without extractions. ${ }^{8,9}$

Regarding stability, it is consensus that anterior open bite is ranked among the most challenging treatments and its end results have been shown to be less stable. However, it is believed that with the establishment of a correct overjet, over bite and muscular balance between the lips and tongue there will be no relapse of the malocclusion.

As may be seen in the record obtained after the end of active treatment, all the goals were attained from both a functional and facial esthetic point of view.

\section{REFERENCES}

\footnotetext{
Moyers RE. Ortodontia. $4^{\text {th }}$ ed. Rio de Janeiro: Guanabara Koogan; 1991.

Van der Linden FP. Genetic and environmental factors in dentofacial morphology. Am J Orthod. 1966:52(8):576-83.

3. Graber TM, Vanarsdal RL. Ortodontia: princípios e técnicas atuais. Rio de Janeiro: Guanabara Koogan; 2002

4. Forte FDS, Bosco VL. Prevalência de mordida aberta anterior e sua relação com hábitos de sucção não nutritiva. Pesq Bras Odontop Clin Integr. 2001;1(1):3-8.

5. Katz CRT. Relação entre hábitos de sucção, mordida aberta anterior, mordida cruzada posterior e morfologia facial em pré-escolares de Recife/PE: um estudo longitudinal [dissertação]. Camaragibe (PE): Universidade de Pernambuco; 2003.

6. Serra-Negra JMC, Pordeus IA, Rocha Junior JF. Estudo da associação entre aleitamento, hábitos bucais e maloclusões. Rev Odontol Univ São Paulo. 1997;11(2):79-86.
}

7. Bishara SE, Cummins DM, Jakobsen JR. The morphologic basis for the extraction decision in class II, division 1 malocclusions: a comparative study. Am J Orthod Dentofacial Orthop. 1995;107(2):129-35.

8. Janson G, Barros SE, de Freitas MR, Henriques JF, Pinzan A. Class II treatment efficiency in maxillary pre-molar extraction and nonextraction protocols. Am J Orthod Dentofacial Orthop. 2007:132(4):490-8

9. Janson G, Barros SEC, Simão TM, Freitas MR. Variáveis relevantes no tratamento da má oclusão de Classe II. Rev Dental Press Ortod Ortop Facial. 2009;14(4):149-57. 